\title{
Teores de pigmentos fotossintéticos, taxa de fotossíntese e estrutura de cloroplastos de plantas jovens de Mikania laevigata Schultz Bip. ex Baker cultivadas sob malhas coloridas
}

\author{
Photosynthetic pigments content, photosynthesis rate and \\ chloroplast structure in young plants of Mikania laevigata Schultz \\ Bip. ex Baker grown under colored nets
}

\author{
Girlene Santos de Souza1*; Evaristo Mauro de Castro²; Ângela Maria Soares²; \\ Anacleto Ranulfo dos Santos ${ }^{3}$; Eduardo Alves ${ }^{4}$
}

\begin{abstract}
Resumo
O guaco (Mikania laevigata) é uma planta medicinal, usada para o tratamento de febre, reumatismo, gripe e doenças do trato respiratório. O entendimento do comportamento fisiológico dessa espécie e as suas respostas às condições do ambiente tornam-se necessários ao aperfeiçoamento dos métodos de cultivo. Nesse contexto, o presente trabalho teve como objetivo avaliar os efeitos do sombreamento com uso de malhas coloridas na concentração de pigmentos fotossintéticos, na taxa de fotossíntese e na ultra-estrutura de cloroplastos de plantas de Mikania laevigata. As plantas foram cultivadas por quatro meses sob malhas de $50 \%$ de sombreamento nas cores azul, vermelha e cinza e a pleno sol ( $0 \%)$. As plantas mantidas a pleno sol tiveram os menores teores de clorofila $a$ e $b$ e o menor teor de carotenóides, enquanto aquelas cultivadas sob malha azul tiveram a maior concentração de clorofilas $a$ e $b$. A menor densidade de cloroplastos foi encontrada nas plantas cultivadas a pleno sol. Nos tratamentos com $50 \%$ de sombreamento, foram verificados cloroplastos mais alongados. Com relação à taxa de fotossíntese potencial, não foi observada nenhuma diferença significativa entre plantas crescidas sob as malhas vermelha, cinza e azul, fato que leva a acreditar que o espectro diferenciado transmitido pelas malhas coloridas não interferiu no aparelho fotossintético do guaco.

Palavras-chave: Guaco, qualidade de luz, intensidade de luz, sombreamento
\end{abstract}

\begin{abstract}
Guaco (Mikania laevigata) is a medicinal plant used to treat fever, rheumatism, flu and respiratory tract diseases. Understanding the physiology of this species and its responses to environmental conditions has become necessary to improving the cultivation methods. In this context, this work aimed to access the effects of shading by using colored nets in on photosynthetic pigment concentration, photosynthetic rate and ultrastructure of chloroplasts of Mikania laevigata. The plants were cultivated during four months under nets with $50 \%$ shading in blue, red and gray color nets and under full sunlight $(0 \%)$. The plants grown under full sunlight had decreased contents of $a$ and $b$ chlorophyll, and of carotenoids, while those grown under blue nets shown higher concentrations of $a$ and $b$ chlorophyll. The lowest density of
\end{abstract}

\footnotetext{
1 Profa Adjunto do Centro de Ciências Agrárias, Ambientais e Biológicas, Universidade Federal do Recôncavo da Bahia, UFRB. Rua Rui Barbosa, 710, Centro, Cruz das Almas, BA, CEP 44.380-000. E-mail: girlene@ufrb.edu.br

2 Profs. Adjuntos do Dept ${ }^{\mathrm{o}}$ de Biologia, Universidade Federal de Lavras, UFLA. Campus Universitário, C P 3037, Lavras, MG, CEP 37.200-000.E-mail: emcastro@ufla.br, amsoares@ufla.br

3 Prof. Associado do CCAAB/UFRB, Cruz das Almas, BA. E-mail: anacleto@ufrb.edu.br

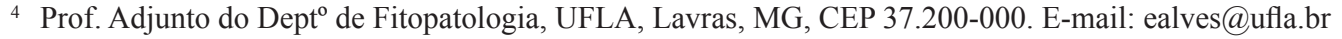

* Autor para correspondência
} 
chloroplasts was found in plants cultivated under full sunlight. Elongated chloroplasts were noticed in treatments with $50 \%$ shading. Regarding the potential rate of photosynthesis no significant change was observed among the plants grown under red, blue and gray nets, which leads to the conclusion that the spectrum transmitted by different coloured nets did not affect guaco photosynthetic apparatus.

Key words: Guaco, light quality, light intensity, shading

Mikania laevigata Schultz Bip. Ex Baker, conhecida vulgarmente como Guaco, pertencente à família Asteraceae, é uma espécie medicinal encontrada nas regiões subtropicais da América do Sul, da África e da Ásia (LORENZI; MATOS, 2003). O guaco é uma das plantas medicinais de maior consumo, utilizada principalmente no tratamento de afecções respiratórias, que age dilatando os brônquios, sendo a cumarina uma das substâncias associadas a esse efeito (PEREIRA et al., 2000).

Tendo em vista sua importância medicinal, investigações a respeito da fisiologia dessa espécie e suas respostas às condições do ambiente tornamse necessárias ao aperfeiçoamento dos métodos de cultivo. Dentre os fatores ambientais, a luz é um recurso fundamental para o desenvolvimento vegetal, pois muitas respostas morfofisiológicas não dependem apenas da presença, atenuação ou ausência da luz, mas também da variação de sua qualidade espectral (MORINI ; MULEO, 2003).

Estudos recentes demonstram que o cultivo sob sombreamento de $50 \%$ com uso de malhas fotoconversoras pode proporcionar várias modificações relacionadas à produção de biomassa e formação de estruturas produtoras de metabólitos (MARTINS, et al., 2009; OLIVEIRA et al., 2009).

As alterações luminosas no ambiente de cultivo proporcionam ajustes do aparelho fotossintético das plantas, os quais resultam na maior eficiência na absorção e transferência de energia para os processos fotossintéticos. Nesse contexto, os teores dos pigmentos cloroplastídicos, clorofila e carotenóides, podem ser utilizados como importantes marcadores de ambientação do vegetal.

Em Arabidopsis, alterações na qualidade da luz promovem variações na quantidade de cloroplastos e em seu movimento nas células (LUESSE; DEBLASIO; HANGARTER, 2006). Shaver, Oldenburg e Bendich (2008) verificaram que modulações na fluência de luz azul alteram a estrutura e as taxas de degradação de DNAs cloroplastídicos e a divisão plastídica em Medicago truncatula.

Segundo Oren-Shamir et al. (2001), as malhas coloridas diferem nos espectros de transmitância da radiação fotossinteticamente ativa. A malha azul apresenta um pico principal de transmitância na região do azul-verde (400-540nm), enquanto que a malha vermelha possui maior transmitância para comprimentos de ondas superiores a 590nm.

Tendo em vista a importância da radiação sob os diversos aspectos fisiológicos e anatômicos nas espécies vegetais, o presente estudo teve por objetivo avaliar os efeitos do cultivo sob malhas de transmissão de luz diferenciada no acúmulo de pigmentos fotossintéticos (clorofila e carotenóides) e na a anatomia dos cloroplastos de plantas jovens de Guaco. O trabalho busca comparar diferentes condições de cultivo que propiciem modificações em tais estruturas, uma vez que estas estão intimamente associadas à captação da energia luminosa e produção de metabólitos utilizados para o crescimento e desenvolvimento do vegetal.

O experimento foi conduzido no período de Março a Agosto de 2006, no Departamento de Biologia, da Universidade Federal de Lavras (UFLA), sob condições de viveiro. As mudas de Guaco foram produzidas a partir de propagação por estacas, retiradas do terço médio dos ramos, provenientes de plantas adultas localizadas no Horto de Plantas Medicinais/UFLA, no município de Lavras, região 
sul de Minas Gerais, a $918 \mathrm{~m}$ de altitude, latitude $21^{\circ} 14^{\prime} \mathrm{S}$ e longitude $45^{\circ} 00^{\prime} \mathrm{W}$ GRW, as quais foram colocadas em bandeja de poliestireno expandido contendo o substrato comercial Plantmax ${ }^{\circledR}$. A propagação das mudas ocorreu em viveiros com $50 \%$ de sombreamento, durante 50 dias.

Após este período, as estacas foram transplantadas para tubos de PVC com capacidade de $3 \mathrm{~L}$, contendo substrato constituído por uma mistura de vermiculita, esterco bovino decomposto e terra de subsolo, na proporção 2:3:5. As plantas foram transferidas para viveiro com nível de sombreamento $50 \%$ de transmitância na região fotossinteticamente ativa, com o uso de malhas coloridas ChromatiNET vermelhas, azul e cinza, fornecidas pela Empresa Polysack Plastic Industries, conforme a especificação do fabricante e um tratamento a pleno sol ( $0 \%$ de sombreamento), como testemunha. Em cada tratamento, foram empregadas 50 mudas, sendo uma planta por vaso, totalizando 200 plantas, com espaçamento de aproximadamente $40 \mathrm{~cm}$ entre os vasos.

A intensidade da radiação foi mensurada por meio de um quantômetrofotômetro-radiômetro LI-COR, modelo LI-185, equipado com um sensor quântico, sendo a radiação solar expressa em $\mu \mathrm{mol} \cdot \mathrm{m}^{-2} \cdot \mathrm{s}^{-1}$. No tratamento a pleno sol, foi observada intensidade de $1.500 \mu \mathrm{mol} . \mathrm{m}^{-2} . \mathrm{s}^{-1}$, correspondendo a $100 \%$ da radiação incidente, sob malha cinza $660 \mu \mathrm{mol} . \mathrm{m}^{-}$ ${ }^{2} \cdot \mathrm{s}^{-1}(44 \%)$, sob malha vermelha $690 \mu$ mol.m ${ }^{2} \cdot \mathrm{s}^{-1}(46 \%)$ e sob malha azul $550 \mu \mathrm{mol} \cdot \mathrm{m}^{-2} \cdot \mathrm{s}^{-1}(36 \%)$.

A determinação dos teores de clorofila e carotenóides foi realizada ao final do experimento, a partir de sete folhas simples completamente expandidas do quarto nó abaixo do ápice das plantas, tomada ao acaso. No momento da coleta as plantas foram acondicionadas em papel de alumínio e refrigeradas em gelo até serem transferidas ao laboratório. A extração e quantificação das clorofilas, $a, b$ e total foram realizadas segundo a metodologia de Arnon (1949), a partir de $1 \mathrm{~g}$ de matéria fresca homogeneizada em $50 \mathrm{~mL}$ de acetona $80 \%$, seguida da leitura em espectofotômetro (Beckman, modelo 640 B) nos comprimentos de onda 645 e $663 \mathrm{~nm}$. A extração e quantificação de carotenóides totais foram realizadas de acordo com a metodologia descrita por Duke e Kenyon (1986), utilizando os coeficientes de absortividade molar de

A avaliação da densidade e anatomia dos cloroplastos foi realizada por microscopia eletrônica de transmissão. Fragmentos de aproximadamente $0,5 \mathrm{~cm}^{2}$ foram retirados da porção mediana de cinco folhas de cada tratamento, localizados no terceiro nó abaixo do ápice, e fixados em solução Karnovsky (glutaraldeído (2,5\%) e paraformaldeído (2,5\%), em tampão cacodilato, $\mathrm{pH} 7,0,0,05 \mathrm{M}+\mathrm{CaCl}_{2} 0,001 \mathrm{M}$ ) por um período de quatro horas em temperatura ambiente. Posteriormente os fragmentos foram lavados em tampão cacodilato $0,05 \mathrm{M}$, pós-fixados em tetróxido de ósmio $1 \%$ com o mesmo tampão por quatro horas. Em seguida o material foi desidratado em concentração crescente de acetona $(35 \%, 50 \%$, $75 \%$, 90\% e 100\%) e incluído em resina Spurr. Os blocos obtidos foram desbastados e cortados em seções semifinos $(1 \mu \mathrm{m})$ e ultrafinas $(<100 \mathrm{~nm})$, utilizando-se um ultramicrotomo Reichrt-Jung, com navalha de diamante.

Os cortes finos foram corados com azul de toluidina e montados permanentemente em meio Permalt para avaliação da densidade dos cloroplastos nas células do parênquima paliçádico em micrsocópio Olympicus CBB. Os cortes ultrafinos foram coletados em grades de ouro (golden slot grids), secos em raques de alumínio cobertos com formvar (ROWLEY; MORAN, 1975). As seções foram pós $\neg$-contrastadas em acetato de uranila, seguido por acetato de chumbo por 3 minutos cada e, em seguida, examinadas em Microscópio Eletrônico de Transmissão Zeiss, modelo EM 902 a $80 \mathrm{Kv}$. As características observadas para as análises ultraestruturais foram o número, a área, perímetro e comprimento dos cloroplastos em células do parênquima paliçádico. Nesse experimento foram avaliados 10 cloroplastos em cada fragmento de folha, totalizando 50 avaliações para cada parâmetro 
analisado.

A medição da fotossíntese potencial (Amax) foi realizada com o auxílio de um monitor de oxigênio. Para esta avaliação foram utilizados três discos foliares de folhas maduras e completamente expandidas de 5 plantas de Guaco com 120 dias de idade.

O experimento foi conduzido seguindo delineamento inteiramente casualizado e os dados obtidos foram submetidos à análise de variância (ANOVA) utilizando-se o programa estatístico SAS Institute (1996). As médias entre os tratamentos foram comparadas pelo teste Scott-Knott, a 5\% de significância.

As concentrações de clorofila apresentaram variações nos tratamentos usados para a espécie de Guaco em estudo (Tabela 1). Nos tratamentos sombreados, foram verificados maiores concentrações de clorofilas e uma menor razão de clorofila $a$ e $b$ em relação às plantas cultivadas a pleno sol. As plantas que cresceram sob malha azul obtiveram maior produção de clorofila $a \mathrm{e}$ $b$, enquanto que nas plantas mantidas sob malha vermelha e cinza foram verificadas concentrações intermediárias. O aumento da proporção de clorofila $b$ nas plantas sombreadas pode ser considerado como característica importante na adaptabilidade vegetal em ambientes sombreados, uma vez que a clorofila $b$ absorve energia em comprimento de onda diferentes da clorofila $a$ e a transfere para o centro de reação, maximizando, assim, a captura energética que efetivamente atua nas reações fotoquímicas (TAIZ; ZEIGER, 2004).

Tabela 1. Teores de clorofila $a, b$ e total $\left(\mathrm{mg} \cdot \mathrm{g}^{-1}\right.$ de matéria fresca) e relação clorofila a/b e teores de carotenóides totais, em folhas de plantas de Mikania laevigata Schultz Bip. Ex. Baker, submetidas a diferentes condições de luminosidade.

Pigmentos Cloroplastídicos

Tratamentos Clorofila a Clorofila b Clorofila total Relação clorofila a/b Carotenóides

\begin{tabular}{llllll}
\hline MalhaVermelha & $2,42 \mathrm{c}^{*}$ & $0,90 \mathrm{c}$ & $3,32 \mathrm{c}$ & $2,10 \mathrm{a}$ & $15,77 \mathrm{a}$ \\
MalhaCinza & $2,56 \mathrm{~b}$ & $1,27 \mathrm{~b}$ & $3,84 \mathrm{~b}$ & $2,01 \mathrm{a}$ & $16,38 \mathrm{~b}$ \\
MalhaAzul & $2,76 \mathrm{a}$ & $2,24 \mathrm{a}$ & $5,02 \mathrm{a}$ & $1,25 \mathrm{~b}$ & $17,65 \mathrm{a}$ \\
Pleno Sol & $1,53 \mathrm{c}$ & $0,75 \mathrm{c}$ & $2,29 \mathrm{~d}$ & $2,37 \mathrm{a}$ & $15,74 \mathrm{a}$
\end{tabular}

*Médias seguidas pela mesma letra, na coluna, não diferem estatisticamente entre si, pelo teste de Scott-Knott, a 5\% de probabilidade.

Essa maior concentração de clorofila b se deve a degradação mais lenta da clorofila b em relação à clorofila a (ENGEL; POGGIANI, 1991) e maior proporção do fotossistema II que émis rico em clorofila b (NAKAZONO et al., 2001). Dessa forma, a capacidade das plantas em maximizar a captura por luz em ambientes sombreados está principlamente realcioanda com a ralação clorofial a/b (ENGEL; POGGIANI, 1991). Lima, Zanella e Castro (2010) verificaram resultados semelhantes, onde os maiores valores da realçao clorofila a/b ocorreram em condições de pleno sol.

O teor de clorofila total foi maior também nas plantas cultivadas sob a malha azul, mostrando, porém, diferenças significativas entre os tratamentos com as malhas vermelha, cinza e a pleno sol (Tabela 1). Resultados estes que podem estar relacionados a uma menor relação vermelho:vermelho-distante (V/VD) existente no ambiente proporcionado pela malha vermelha, o que está de acordo com os resultados encontrados Kasperbauer (1987), que observaram menor conteúdo de clorofila por 
unidade de área em tabaco por apresentarem uma baixa relação V/VD.

Em plantas a pleno sol, o teor de clorofilas $a, b$ e total foi reduzido em relação às plantas dispostas sob sombreamentos. Diversos trabalhos, como os de Atroch et al. (2001), Castro et al. (2005), Engel e Poggiani (1991), Lee et al. (2000), Lima Júnior, Alvarenga e Castro (2006), Martins et al. (2009) e Oliveira et al. (2009), também relatam maiores teores de clorofilas em plantas sombreadas em relação às de pleno sol.

Apesar de um menor teor de clorofila total encontrado nas plantas de Guaco cultivadas a pleno sol, estas tiveram numericamente, maior relação clorofila $a / b$ quando comparadas aos demais tratamentos, porém não diferiram entre si (Tabela 1). Esta redução se deve ao fato da menor irradiância experimentada pelos tratamentos sob as malhas coloridas. Estes resultados revelam que plantas de Guaco dispõem de diferentes estratégias no acúmulo e uso de pigmentos fotossintéticos em ambientes com variações na disponibilidade e composição espectral da luz.

A razão entre a clorofiala $a$ e $b$ de maneira geral, diminui com a redução da intensidade luminosa (BOARDMAN, 1977), devido a uma maior proporção relativa de clorofila $b$ em ambientes sombreados, que pode estar associada à sua degradação mais lenta em relação à clorofila a (ENGEL; POGGIANI, 1991). Estes resultados concordam com os obtidos por Atroch et al. (2001), Lee et al. (2000), Castro et al. (2005).

Entretanto, para algumas espécies como Myrtus communis L., não foi encontrada diferença significativa na relação clorofila $a / b$ em plantas cultivadas a pleno sol ou $30 \%$ de irradiância (MENDES; GAZARINI; RODRIGUES, 2001). Contudo, o teor de clorofila $b$ em folhas de angico branco foi 3,6 vezes inferior no final do inverno, em comparação ao final do verão, quando as irradiâncias correspondiam a $13 \mathrm{MJ} \mathrm{m}^{-2} \mathrm{dia}^{-1}$ e $17 \mathrm{MJ} \mathrm{m}^{-2} \mathrm{dia}^{-1}$, respectivamente ( FREIBERGER et al., 2010)
A luz azul influencia a biossíntese de clorofila e outros pigmentos através da regulação da expressão de determinados genes (TSUNOYAMA et al., 2002). Isto pode explicar o maior vigor foliar encontrado para todas as variedades tratadas com malha azul. Embora não tenha sido avaliado formalmente, as folhas das plantas tratadas com luz azul apresentavam-se mais verdes e brilhantes, para plantas de Guaco.

Segundo Larcher (2004), ecologicamente, as alterações na biossíntese de clorofilas pelas variações espectrais podem proporcionar vantagens quanto ao crescimento e sucesso reprodutivo das espécies vegetais. Assim, os resultados indicam a ocorrência de uma adaptação cromática do Guaco que possivelmente auxilie no seu desempenho fotossintético.

Quanto aos teores de carotenóides pode-se verificar, no tabela 1, que nas plantas de Guaco a malha cinza diferiu das malhas vermelha $\mathrm{e}$ azul, diferindo também das plantas cultivadas em condições de pleno sol. Observa-se que o maior valor foi obtido pelas mudas mantidas em sombreamento com as malhas azul e cinza e o menor valor pelas mudas cultivadas a condições de pleno sol. De acordo Oren Shamir et al. (2001), o ambiente sombreado com malha azul apresenta maior transmitância da luz na faixa do azul (400$500 \mathrm{~nm}$ ), indicando que o balanço energético possa favorecer a absorção de energia pelos carotenóides e, uma vez que estes estão associados às moléculas de clorofilas dos sistemas antenas e aos centros de reação, tem a capacidade auxiliar o desempenho fotossintético por meio de transferência de energia absorvida para as clorofilas.

Diferentemente dos resultados encontrados neste trabalho, Gonçalves et al. (2003) que avaliaram a concentração de pigmentos fotossintéticos em mogno e cumaru, sob dois ambientes de luz, verificaram que os teores de carotenóides (mg.g${ }^{1} \mathrm{MF}$ ) foram sempre maiores no ambiente de sol e resultados encontrados por McMahon e Kelly 
(1995), mostraram que plantas de crisântemo cultivadas sob filtro de sulfato de cobre que reduz a transmissão da luz VD, apresentaram maiores conteúdos de carotenóides, como também de clorofila $a$ e $b$, quando comparado às plantas cultivadas sob filtro de tinta azul, que receberam uma menor relação V/VD.

Garcia-Plazaola, Artetxe e Becerril (1999), em trabalhos com Quercus ilex, observaram aumentos consideráveis nos teores de carotenóides e antioxidantes (ascorbato, glutationa e $\alpha$-tocoferol) em folhas a pleno sol em relação às folhas de sombra, e atribuíram esse fenômeno à capacidade de resistência à fotooxidação por excesso de luz.

Os resultados de Lima, Zanella e Castro (2010), confirmaram que os maiores valores de carotenóides foram adquiridos quando plantas de Hymenaea courbaril e Enterolobium contortisiliquum foram cultivadas sob sombreamento, diferindo daquelas cultivadas a pleno sol. Geralmente os carotenóides tendem a aumentar com a redução da intensidade luminosa. Esses pigmentos durante a fotossíntese desempenham funções como absorção de luz nos complexos de captação de luz atuando como pigmentos acessórios e atuando como fotorreceptores do aparato fotoquímico (KERBAUY, 2004).

Os baixos teores de pigmentos fotossintéticos (carotenóides e clorofila total), observados nas plantas cultivadas a pleno sol podem indicar a ocorrência da fotoinibição nestas plantas, devido à radiação, no que se refere à captação de luz em ambientes de menor luminosidade e à proteção contra a fotodestruição em ambiente de maior luminosidade (GOMES et al., 2008). A luz absorvida pelos carotenóides é transferida à clorofila para o processo de fotossíntese. Logo, as plantas sob malha azul foram, provavelmente, beneficiadas na captação de radiação em relação às demais sombreadas, uma vez que os carotenóides absorvem a luz na região dos 400-500 nm, faixa da luz azul do espectro.

A taxa de fotossíntese potencial, não mostrou nenhuma diferença significativa nas plantas crescidas sob as malhas vermelha, cinza e azul (Figura 1), fato que leva a acreditar que o espectro diferenciado transmitido pelas malhas coloridas não interferiu no aparelho fotossintético da espécie de Guaco em estudo. As plantas da malha azul, aparentemente apresentaram altas taxas, em torno de $12,01 \mu \mathrm{mol} \mathrm{O} 2 . \mathrm{m}^{2} \mathrm{~s}^{-1}$, enquanto que essas medidas foram mais baixas sob a malha cinza (Figura 1) quando comparada com a malha vermelha. As folhas crescidas em condições de pleno sol também apresentaram uma taxa fotossintética mais alta que as folhas crescidas em condições de sombreamento sob a malha vermelha e azul. Oren-Shamir et al. (2001) verificaram resultados contrários, onde as maiores taxas fotossintéticas das plantas de Pittosporum ocorreram em plantas crescidas sob a malha cinza. Segundo estes autores estas taxas fotossintéticas poderiam depender em parte do nível da variegação foliar, ou seja, com mais variegação significa menos área verde. Assim a malha cinza causou menos variegação e altas taxas fotossintéticas, enquanto mais variegação e menos taxas ocorreram sob a malha azul.

Entretanto, nas folhas de Convallaria majalis, uma espécie $\mathrm{C}_{3}$ do tipo sombra, a luz azul aumentou atividade fotossintética nestas plantas quando comparada com a luz vermelha (BUKHOV; DROZDOVA; BONDAR, 1995). Segundo estes autores a qualidade de luz afeta a curva de fotossíntese de maneira complexa e depende em parte da origem ecológica da planta.

A intensidade e a qualidade de luz são de significância considerável para a conversão da energia química no processo fotossintético, como também para alguns efeitos morfogênicos, os quais podem ser observados pelas variações no tamanho das folhas. Além disso, a plasticidade adaptativa das espécies, associada ao acúmulo de biomassa depende do ajuste de seu aparelho fotossintético e estão sujeitos às diferentes condições de radiação solar (ATTRIDGE, 1990). 
Figura 1. Fotossíntese total de plantas de Mikania laevigata submetidas ao sombreamento com malha colorida durante 120 dias. (1) Malha vermelha, (2) Malha cinza, (3) Malha azul e (4) Pleno sol. Barras seguidas da mesma letra não diferem significativamente entre si, pelo teste Scott-Knott, a 5\% de probabilidade.

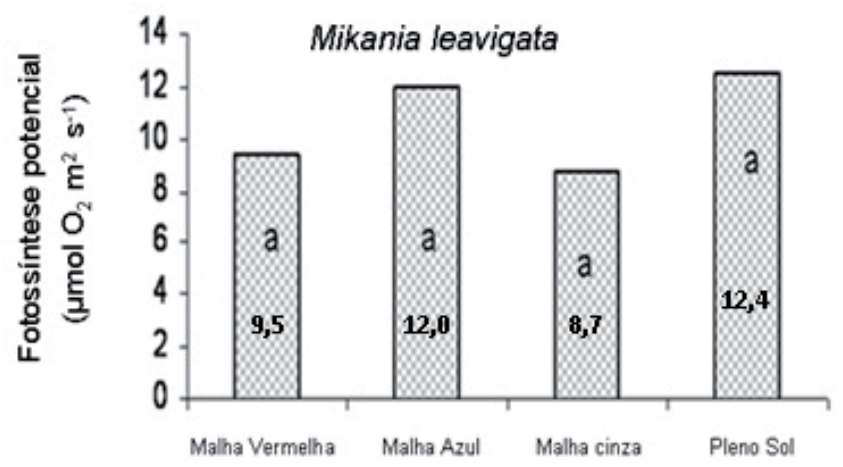

Tratamentos

$\mathrm{O}$ fato de transmitir menos radiação fotossinteticamente ativa não impediu as plantas cultivadas sob a malha azul acumularem maior massa seca total ainda que as outras malhas também propiciassem quantidade de radiação dentro do limite tido como ideal pela literatura científica, portanto tal resultado torna necessário estudos futuros sobre os aspectos do desenvolvimento vegetativo de plantas cultivadas nestas condições.

A ultra-estrutura dos cloroplastos de lâminas foliares de Guaco é mostrada na Figura 2. Observa-se que a estrutura e o tamanho dos cloroplastos sofreram alterações, em virtude do ambiente de cultivo. Nos tratamentos a pleno sol, sob malhas cinza e vermelha, não foram observadas diferenças significativas quanto ao número de cloroplasto (Tabela 2); nas plantas crescidas sob malha azul, foi evidenciada a maior quantidade de cloroplastos por célula, a qual diferiu dos demais tratamentos. A luz azul é importante para o desenvolvimento de cloroplastos e tem se mostrado mais eficiente que a luz vermelha (SCHUERGER; BROWN; STRYJEWSKI, 1997). No entanto, a exposição à luz vermelha e vermelha distante, durante o crescimento e desenvolvimento foliar, influencia significativamente o desenvolvimento dos cloroplastos (LEONG; GOODCHILD; ANDERSON, 1985).

Em todos os tratamentos, os cloroplastos foram observados próximos à parede celular; somente nas plantas mantidas sob malha vermelha algumas dessas organelas encontram-se dispersas no meio intracelular. De acordo com alguns autores, espécies com mesofilo dorsiventral apresentam a grande maioria dos cloroplastos encontrados nas células do parênquima paliçádico. Devido à forma e ao arranjo dessas células, os cloroplastos podem se dispor paralelamente às paredes celulares, aumentando a eficiência fotossintética ou reduzindo os danos pelo excesso de luz (MENEZES; SILVA; PINNA, 2003).

Pelos resultados, constata-se que os maiores comprimentos de cloroplastos foram observados nas lâminas foliares submetidas aos tratamentos de pleno sol e sob a malha vermelha, em relação às submetidas ao sombreamento com as malhas azul e cinza, o que caracterizou a presença de organelas mais alongadas. Quanto à área e ao perímetro dos cloroplastos, nota-se que houve um aumento nas plantas mentidas em pleno sol (Tabela 2). 
Figura 2. Eletromicrografias de transmissão de cloroplastos e grãos de amido em células do parênquima paliçádico de lâminas foliares de Mikania laevigata submetidas a diferentes ambientes de luz com malhas coloridos. (A) Malha vermelha, (B) Malha cinza, (C) Malha azul e (D) Pleno sol. Barra= $1 \mu \mathrm{m}$. CL: cloroplasto; E: espaço intercelular; G: grão de amido no interior do cloroplasto; P: parede celular; M: Mitocôndria.

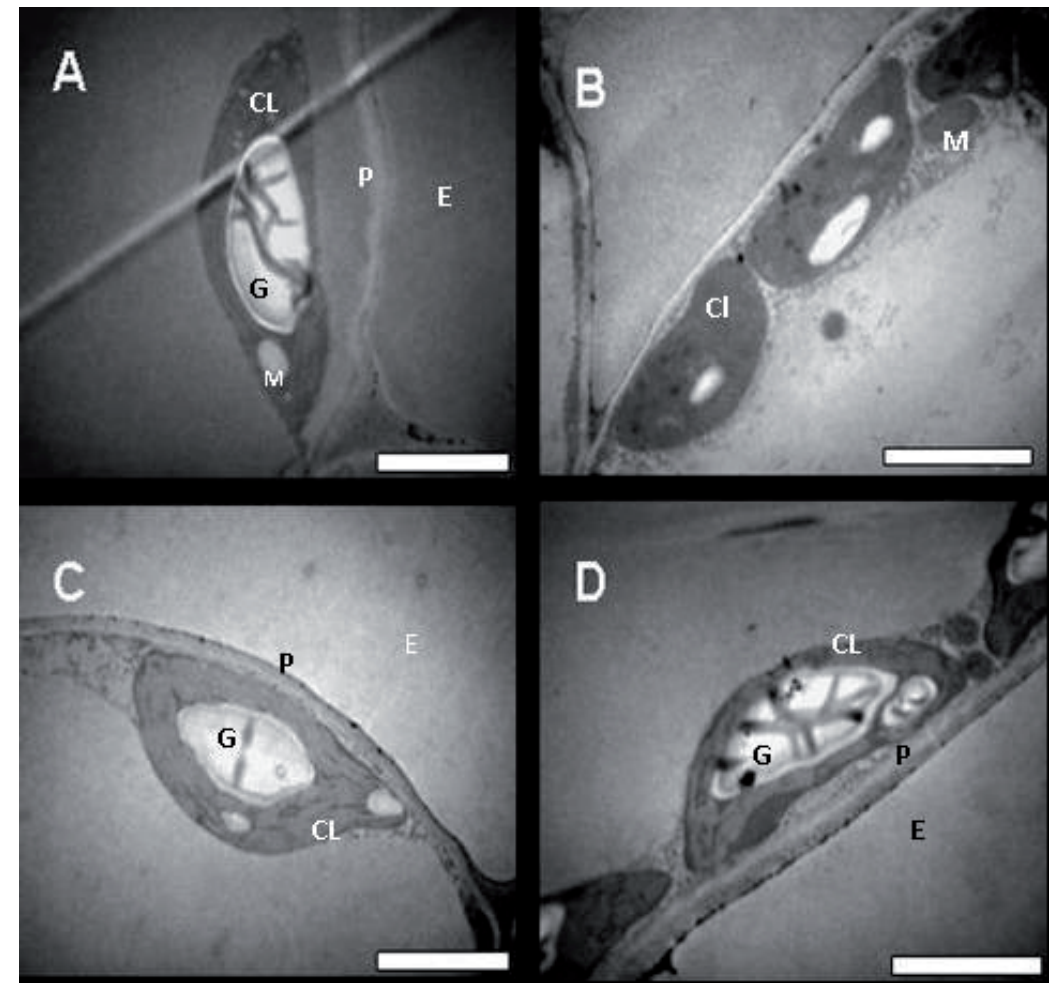

Tabela 2. Valores médios das características cloroplastídicas do tecido paliçádico de plantas jovens de Mikania laevigata submetidas a diferentes condições de luminosidades, com 50\% de sombreamento sob malhas. Legenda: Dens=densidade; Perim=perímetro; Comp=comprimento.

\begin{tabular}{|c|c|c|c|c|c|c|c|}
\hline \multirow[t]{2}{*}{ Tratamento } & \multicolumn{5}{|c|}{ Cloroplastos } & \multicolumn{2}{|c|}{ Grãos de Amido } \\
\hline & $\begin{array}{c}\text { Dens } \\
\left(\mathrm{N}^{\mathbf{0}} \text { célula }^{-1}\right)\end{array}$ & $\begin{array}{l}\text { Área } \\
\left(\mu \mathrm{m}^{2}\right)\end{array}$ & $\begin{array}{r}\text { Perim } \\
(\mu \mathrm{m})\end{array}$ & $\begin{array}{c}\text { Comp } \\
(\mu \mathrm{m})\end{array}$ & $\begin{array}{c}\text { Largura } \\
(\mu \mathrm{m})\end{array}$ & $\begin{array}{r}\text { Área } \\
\left(\mu \mathrm{m}^{2}\right)\end{array}$ & $\begin{array}{c}\text { Perim } \\
(\mu \mathrm{m})\end{array}$ \\
\hline Malha Vermelha & $3,75 b^{*}$ & $7,74 \mathrm{a}$ & $14,07 \mathrm{a}$ & $5,86 \mathrm{a}$ & $1,86 \mathrm{~b}$ & $2,83 \mathrm{~b}$ & $12,71 \mathrm{~b}$ \\
\hline Malha Cinza & $4,25 \mathrm{~b}$ & $4,85 \mathrm{~b}$ & $9,44 \mathrm{c}$ & $3,36 \mathrm{~b}$ & $1,91 \mathrm{~b}$ & $2,30 \mathrm{c}$ & $10,35 \mathrm{c}$ \\
\hline Malha Azul & $5,87 \mathrm{a}$ & $8,04 \mathrm{a}$ & $11,89 \mathrm{~b}$ & $4,06 \mathrm{~b}$ & $2,49 \mathrm{a}$ & $3,55 \mathrm{a}$ & $13,78 \mathrm{a}$ \\
\hline Pleno Sol & $3,25 \mathrm{~b}$ & $8,55 \mathrm{a}$ & $14,41 \mathrm{a}$ & $5,96 \mathrm{a}$ & $2,09 a b$ & $3,70 \mathrm{a}$ & $14,24 \mathrm{a}$ \\
\hline
\end{tabular}

*Médias seguidas pela mesma letra na coluna, não diferem estatisticamente entre si, pelo teste Scott-Knott a $\mathrm{P} \leq 0,05$ $(\mathrm{n}=10)$.

Nery et al. (2007) observaram que a estrutura e o tamanho dos cloroplastos de gaunandi mudaram de acordo com a condição de luminosidade e que não foram observadas diferenças quanto ao número de cloroplastos por célula entre os níveis de sombreamento, variando entre 6 e 7 cloroplastos por célula.

Em todos os tratamentos, verificou-se a presença 
de grãos de amido (Figura 1) e estes não diferiram significativamente quanto à área e o perímetro nos tratamentos a pleno sol e sob malha azul. Nas plantas crescidas sob malha cinza, foram observados os menores valores de área e perímetro; as plantas mantidas sob malha vermelha apresentaram valores intermediários para estas características (Tabela 2). Isso indica que essas condições de cultivo podem proporcionar maiores acúmulos de reserva energética nas células do mesofilo, sendo uma característica vantajosa para o crescimento e a produtividade de plantas de Guaco.

Plantas que crescem sob forte radiação desenvolvem células no mesofilo ricas em cloroplasto e têm uma maior produção e um maior conteúdo energético da matéria seca. No entanto, diante dos resultados, observa-se que não apenas a intensidade, mas também a qualidade de luz é determinante para que se desenvolvam células do mesofilo ricas em cloroplastos e grãos de amido com dimensões similares.

O cultivo sob malha azul proporciona a produção de cloroplastos com maior reserva energética evitando a alta produção de carotenóides. Essas mudanças verificadas nas concentrações dos pigmentos e na estrutura dos cloroplastos evidenciam uma adaptação do Guaco, a qual apresenta grande plasticidade fenotípica em função dos tratamentos de qualidade de luz, à variação cromática que objetiva melhorar o desempenho fotossintético e permite inferir que o controle na radiação luminosa pode ser usado no cultivo dessa espécie para otimizar seu crescimento e sua produtividade.

Nas condições em que o trabalho foi conduzido pode-se concluir que plantas guaco se adaptaram melhor ao ambiente sombreado, o qual influenciou positivamente as características associadas aos pigmentos fotossintéticos e à fotossíntese potencial, independente da radiação transmitida pelas malhas coloridas, enquanto que as plantas cultivadas a pleno sol apresentaram baixos teores de pigmentos foliares e sinais aparentes de fotoinibição.

\section{Referências}

ARNON, D. I. Copper enzymes in isolates choroplasts. Polyphenoloxidade in Beta vulgaris. Plant Physiology, Palo Alto, v. 24, n. 1, p. 1-15, 1949.

ATROCH, E. M. A. C.; SOARES, A. M.; ALVARENGA, A. A.; CASTRO, E. M. Crescimento, teor de clorofilas, distribuição de biomassa e características anatômicas de plantas jovens de Bauhinia forficata Link. submetidas a diferentes condições de sombreamento. Ciência e Agrotecnologia, Lavras, v. 25, n. 4, p. 853-862, 2001.

ATTRIDGE, T. H. Light and plant responses. London: E. Arnold, 1990. 147 p.

BOARDMAN, N. K. Comparative photosynthesis of sun and shade plants. Annual Review of Plant Physiology, Palo Alto, v. 28, n. 1, p. 355-377, 1977.

BUKHOV, N. G.; DROZDOVA, I. S.; BONDAR, V. V. Light response curves of photosynthesis in leaves of suntype and shade-type plants grown in blue or red light. Journal of Photochemistry and Photobiology B; Biology, Moscow, v. 30, n. 1, p. 39-41, 1995.

CASTRO, E. M.; PINTO, J. E. B. P.; MELO, H. C.; SOARES, A. M.; ALVARENGA, A. A.; LIMA JÚNIOR, E. C. Aspectos anatômicos e fisiológicos de plantas de Guaco submetidas a fotoperíodos. Horticultura Brasileira, Brasília, v. 23, n. 3, p. 846-850, 2005.

DUKE, S. O.; KENYON, W. H. Effects of dimethazone (FMC 57020) on chloroplast development II. Pigment synthesis and photosynthetic function in cowpea (Vigna unguiculata L.) primary leaves. Pesticide Biochemistry and Physiology, Stoneville, v. 25, n. 1, p. 11-18, 1986.

ENGEL, V. L.; POGGIANI, F. Estudo da concentração de clorofilas nas folhas e seu espectro de absorção de luz em função do sombreamento em mudas de quatro espécies florestais nativas. Revista Brasileira de Fisiologia Vegetal, Brasília, v. 3, n. 1, p. 39-45, 1991.

FREIBERGER, M. B.; CASTOLDI, G.; MARINI, D.; LANG, A.; HERZOG, N. F. M.; MALAVASI, U. C. Variação sazonal de clorofilas em folhas de Tabebuia avellanedae e Anadenanthera colubrina. Semina: Ciências Agrárias, Londrina, v. 31, p. 1343-1348, 2010. Suplemento 1.

GARCIA-PLAZAOLA, J. I.; ARTETXE, U.; BECERRIL, J. M. Diurnal changes in antioxidant and carotenoid composition in the Mediterranean schlerophyll tree Quercus ilex (L.) during winter. Plant Science, Bibao, v. 143, n. 2, p. 125-133, 1999.

GOMES, I. A. C.; CASTRO, E. M.; SOARES, A. M.; ALVES, J. D.; ALVARENGA, M. I. N.; ALVES, E.; BARBOSA, J. P. R. A. D.; FRIES, D. D. Alterações 
morfofisiológicas em folhas de Coffea arabica L. cv. Oeiras sob influêcia do sombreamento por Acacia mangium Willd. Ciência Rural, Santa Maria, v. 38, n. 1, p. 109-115, 2008.

GONÇALVES, L. A.; BARBOSA, L. C. A.; AZEVEDO, A. A.; CASAli, V. W. D.; NASCIMENTO, E. A. Produção e composição do óleo essencial de alfavaquinha (Ocimum selloi Benth.) em resposta a dois níveis de radiação solar. Revista Brasileira de Plantas Medicinais, Botucatu, v. 6, n. 1, p. 8-14, 2003.

KASPERBAUER, M. J. Far-red light reflection from green leaves and effects on phytochrome-mediated assimilate partitioning under field conditions. Plant Physiology, Florence, v. 85, n. 2, p. 350-354, 1987.

KERBAUY, G. B. Fisiologia vegetal. Rio de Janeiro: Guanabara Koogan, 2004. 452 p.

LARCHER, W. Ecofisiologia vegetal. São Carlos: RiMA Artes e Textos, 2004. 531 p.

LEE, D. W.; OBERBAUER, F.; JOHNSON, P.; BASKARAN, K.; MANSOR, M.; MOHAMAD, H.; YAP, S. K. Effects of irradiance and spectral quality on leaf structure and function in seedlings of two southeast asian Hopea (Dipterocarpaceae) species. American Journal of Botany, Miami, v. 87, n. 4, p. 447-455, 2000.

LEONG, T.; GOODCHILD, D. J.; ANDERSON, J. M. Effect of light quality on the composition, function and structure of photosynthetic thylakoid membranes of Asplenium australicum (Sm.) Hook. Plant Physiology, Palo Alto, v. 78, n. 3, p. 561-567, 1985.

LIMA JUNIOR, E. C.; ALVARENGA, A. A.; CASTRO, E. M. Physioanatomy traits of leaves in young plants of Cupania vernalis camb. subjected to different shading levels. Revista Árvore, Viçosa, v. 30, n. 1, p. 33-41, 2006.

LIMA, A. L. S.; ZANELlA, F.; CASTRO, L. D. M. Crescimento de Hymenaea courbaril L. var. stilbocarpa (Hayne) Lee et Lang. e Enterolobium contortisiliquum (Vell.) Morong (Leguminosae) sob diferentes níveis de sombreamento. Acta Amazônica, Manaus, v. 40, n. 1, p. 43-48, 2010.

LORENZI, H.; MATOS, F. J. A. Plantas medicinais no Brasil: nativas e exóticas. Nova Odessa: Instituto Plantarum, 2003. 254 p.

LUESSE, S. L.; DEBLASIO, S. L.; HANGARTER, R. P. Plastid movement impaired 2, a new gene involved in normal blue-light-induced chloroplast movements in Arabidopsis. Plant Physiology, Palo Alto, v. 141, n. 4, p. 1328-1337, 2006.

MARTINS, J. R.; ALVARENGA, A. A.; CASTRO, E. M.; SIlVA, A. P. O.; OLIVEIRA, C.; ALVES, E.
Anatomia foliar de plantas de alfavaca-cravo cultivadas sob malhas coloridas. Ciência Rural, Santa Maria, v. 39, n. 1, p. 82-87, 2009.

MCMAHON, M. J.; KELLY, J. W. Anatomy and pigments of chrysanthemum leaves developed under spectrally selective filters. Scientia Horticulturae, Turquia, v. 64, n. 3, p. 203-209, 1995.

MENDES, M. M.; GAZARINI, L. C.; RODRIGUES, M. L. Acclimation of Myrtus communis to contrasting mediterranean light environment - effects on structure and chemical composition of foliage and plant water relations. Environment and Experimental Botany, Lisboa, v. 45, n. 2, p. 165-178, 2001.

MENEZES, N. L.; SILVA, D. C.; PINNA, G. F. M. Folha. In: APPEZZATO-DAGLÓRIA, B.; CARMELLOGUERREIRO, S. M. (Ed.). Anatomia vegetal. Viçosa, MG: UFV, 2003. p. 303-311.

MORINI, S.; MULEO, R. Effects of light quality on micropropagation of woody species. In: JAIN, S. M.; ISHII, K. (Ed.). Micropropagation of woody trees and fruits. Dordrecht: Kluwer Academic, 2003. p. 3-35.

NAKAZONO, E. M.; DACOSTA, M.; FUTATSUGI, K.; PAULILO, M. T. S. Early growth of Euterpe edulis Mart., in different light environments. Revista Brasileira de Botânica, São Paulo, v. 24, n. 2, p. 173-179, 2001.

NERY, F. C.; ALVARENGA, A. A.; JUSTO, C. F.; CASTRO, E. M.; SOUZA, G. S.; ALVES, E. Aspectos anatômicos de folhas de plantas jovens de Calophyllum brasiliense Cambess. submetidas a diferentes níveis de sombreamento. Revista Brasileira de Biociências, Porto Alegre, v. 5, p. 129-131, 2007. Suplemento 2.

OLIVEIRA, M. I.; CASTRO, E. M.; COSTA, L. C. B.; OLIVEIRA, C. Características biométricas, anatômicas e fisiológicas de Artemisia vulgaris L. cultivada sob telas coloridas. Revista Brasileira de Plantas Medicinais, Botucatu, v. 11, n. 1, p. 56-62, 2009.

OREN-SHAMIR, M.; GUSSAKOVSKY, E. E.; SHPIEGEL, E.; NISSIM-LEVI, A.; RATNER, K.; OVADIA, R.; GILLER, Y. E.; SHAHAK, Y. Coloured shade nets can improve the yield and quality of green decorative branches of Pittosporum variegatum. The Journal of Horticultural Science and Biotechnology, v. 76, n. 3, p. 353-361, 2001.

PEREIRA, A. M. S.; CÂMARA, F. L. A.; CELEGHINI, R. M. S.; VILEGAS, J. H. Y.; LANÇAS, F. M.; FRANÇA, S. C. Seasonal variation in coumarin contento of Mikania glomerata. Journal of Herbs Spices e Medicinal Plants, v. 7, n. 2, p. 1-10, 2000.

ROWLEY, C. R.; MORAN, D. T. A simple procedure 
for mounting wrinkle free section on formvar-coated slot grids. Ultramicrotomy, Amsterdam, v. 1, n. 2, p. 151-155, 1975.

SAS INSTITUTE. The SAS-system for Windows: release 6.08. Cary: SAS Institute, 1996. (Software).

SCHUERGER, A. C.; BROWN, C. S.; STRYJEWSKI, E. C. Anatomic features of pepper plants (Capsicum annuum L.) grown under red light-emitting diodes supplemented with blue or far-red light. Annals of Botany, London, v. 79, n. 3, p. 273-282, 1997.

SHAVER, D. J.; OLDENBURG, D. J.; BENDICH, A. J. The structure of chloroplast DNA molecules and the effects of light on the amount of chloroplast DNA during development in Medicago truncatula. Plant Physiology, Palo Alto, v. 146, n. 3, p. 1064-1074, 2008.

TAIZ, L.; ZEIGER, E. Fisiologia vegetal. 3. ed. Porto Alegre: Artmed, 2004. 719 p.

TSUNOYAMA, Y.; MORIKAWA, K.; SHIINA, T.; TOYOSHIMA, Y. Blue light specific and differential expression of plastid sigma factor, Sig5 in Arabdopsis thaliana. FEBS lett, Sakyo-ku, v. 516, n. 1, p. 225-228, 2002. 
